doses, has been found most potent for good in peritonitis. I have found it very beneficial in pleurisy. Practitioners will, at no distant day, lose their dread of the drug in meningitis and in pericarditis.

In conclusion, then, let me draw the attention of the profession to the important fact we have developed, that we prescribe, even to the saturation of the system, a medicine which directly promotes that which we least desire-the effusion of serum. Opium and its alkaloid act most beneficially in all cases (except the syphilitic) in which our text-books advise us to use mercurial preparations.

\section{A CASE OF COMPOUND FRACTURE OF THE CRANIUM, FOLLOWED BY APHASIA.}

By Cari H. Smith, M.D., of Kenton, Ohio.

S. Z., aged 34, admitted to Dennison (U.S.A.) General Hospital, Aug. 10, 1864 ; cause of injury, railroad accident. When brought to the hospital, he was unconscious, and was at once operated on. He lost one and one fourth ounce of brain during the operation of removing fractured bones. He remained in a semi-conscious condition for six weeks, being fed by the mouth and rectum, as the case would admit of. After the lapse of two months he began to look about himself, but had lost the use of his speech. His intellect seemed to be in perfect order, memory alone being disordered in its relation to language. He remained in this condition for three months, when, with the help of nurses and others, he began to learn word after word, just as if he had never secn a letter. It was about eight months before he was able to converse at all, and then he would halt in quest of words. He was not affected with paralysis during his convalescence.

\section{POISONING BY BROMIDE OF POTASH.}

Mr. EDItor,-The following case, as related to me by my friend, Dr. J. O. Taylor, U.S.A., may be of interest to some of your readers. Private Jas. Walla (colored), Co. C., 39th U.S. Infantry, had been under treatment for some weeks for intermittent, and finally was admitted to hospital Feb. 17th, 1868, laboring under a severe attack of asthma. On the morning of the 18th, potass. bromid. gr. $\mathrm{xx}$. was prescribed, to be given at 9 , A.M., and at intervals of six hours through the day in the same dose.
The medicine was administered as ordered. The Dr. having occasion to visit the hospital at 10, A.M., found the patient suffering much agony in the region of the stomach, with repeated retchings and emesis. He complained that the "medicine had poisoned him;" and, on inspecting the mouth, the mucous membrane of the fauces was found to be highly injected, while the tongue presented every appearance of the effects of a corrosive poison. Diarrhœa also was present, and on using cloths they were found to be stained violet color. Two fluid drachms of aromatic spirits of ammonia, in half a tumbler of water, were at once administered, to the great relief of the sufferer. This was thrice repeated at half hour intervals, and mucilaginous drinks were prescribed for the rest of the day. The patient was finally relieved. It is to be remarked that no food had been taken for twenty-four hours previously, which may readily account for the rapid disintregation of the salt in the stomach and liberation of bromine.

Brighton, Mass., March 6, 1868.

\section{agospital Meports.}

\section{BOSTON CITY HOSPITAL.}

Reported by F. C. Ropes, M.D., one of the Visiting Surgeons.

Case I.-(Service of Dr. Cheever.)-J. D. S., aged 47 , blacksmith, entered hospital on Jan. 2d, 1868, having received a deep punctured wound of the wrist from a piece of steel, which flew from a chisel while he was at work. The accident occurred shortly before entrance. The wound was situated close to the outer side of the base of the metacarpal bone of the thumb, and severed the radial artery. Patient states that he thinks he lost a pint of blood at the time of the accident. A surgeon was summoned, who tied the artery in the wound. On entrance, no hæmorrhage. Slight compression made over wound.

Jan. 6th. - No return of hæmorrhage. Wound healing rapidly.

14th.--Hand somewhat red and swollen. Poultice applied.

18th.-Wound strapped with stickingplaster. Omit poultice.

25th.-Discharged, nearly well.

CASE II. - (Service of Dr. Cheever.)-D. F. C., æt. 33, entered hospital on May 30, 1866. While walking in the street, was assaulted by a man, who inflicted a stab with a knife, which entered near the flex- 